\title{
Does the contraceptive pill influence peak nasal inspiratory
}

\section{flow values?*}

Giancarlo Ottaviano', Erich Cosmi², Valentina lacono', Bruno Scarpa ${ }^{3}$, Alberto Staffieri', Glenis K. Scadding ${ }^{4}$

'Department of Neurosciences, Otolaryngology Section, University of Padova, Padova, Italy

2 Department of Woman and Child Health, University of Padova, Padova, Italy

${ }^{3}$ Department of Statistics, University of Padova, Padova, Italy

${ }^{4}$ Royal National Throat, Nose and Ear Hospital, London, United Kingdom
Rhinology 52: 355-359, 2014

DOl:10.4193/Rhino14.004

*Received for publication:

January 9, 2014

Accepted: March 26, 2014

\begin{abstract}
Background: Early oral contraceptive pills (OCP) had higher estrogen levels and have been thought to cause nasal obstruction in about $40 \%$ of women users. A recent small study conducted on women taking OCP showed no significant effects on nasal patency. The aim of the present study was to analyse in a large number of volunteers if Peak Nasal Inspiratory Flow (PNIF) values could be influenced by modern OCP.
\end{abstract}

Methodology: PNIF was measured in 257 women (from 14 to 51 years old), divided into two groups: the study group composed of 109 healthy women taking modern OCP; the control group composed of 148 healthy women who did not take OCP. 9 women in the study group were excluded because of allergic disease, 248 females were finally considered. Data were statistically analysed and figures/tables were produced to see the effect of OCP on PNIF.

Results: The present study could not show any effect of OCP on nasal function. Moreover, while height influenced PNIF in both groups, age was not statistically significant.

Conclusion: From the present study, it seems that OCP could have no effects on nasal airflow, confirming that modern OCP with lower estrogen doses should not affect nasal mucosa or nasal patency.

Key words: contraception, nasal patency, oral pill, females, height

\section{Introduction}

In clinical practice patients report nasal obstruction as consequence of side effects of systemic medications taken for nonnasal conditions ${ }^{(1)}$. Recently there has been interest in studying the effect of sexual hormones on non-genital targets which present estrogen receptors, such as the respiratory nasal mucosa ${ }^{(2)}$. Histopathological and histochemical changes occur in the guinea pig respiratory nasal mucosa after receiving ethynylestradiol (3). These changes, where most of the epithelial cilia were lost or detached, are similar to those observed on the nasal mucosa of symptomatic human females ${ }^{(4)}$.

Early OCP had higher estrogen levels (about $50 \mu \mathrm{g}$ of estradiol) and have been thought to cause nasal obstruction in about
$40 \%$ of women users ${ }^{(5)}$. Female hormones related rhinitis has been associated to snoring ${ }^{(6)}$ and other nasal symptoms, such as nasal obstruction, clear rhinorrhea and epistaxis ${ }^{(7)}$, which may deserve medical treatment ${ }^{(8)}$. Nevertheless, a recent study conducted on 11 women taking combined OCP (containing 20-35 $\mu \mathrm{g}$ of estradiol) showed no significant effects on nasal physiology, including nasal patency ${ }^{(5)}$.

The measurement of PNIF provides a simple, cheap, fast and highly reproducible tool for determining the extent of nasal airway patency ${ }^{\left({ }^{9}\right.}$. In previous works, we attempted to study normal adult PNIF levels and all women taking OCP were excluded, as we were worried it could have affected nasal patency ${ }^{(10-13)}$. The aim of the present study was to analyse, in a large number 
of volunteers, if PNIF values could be influenced by OCP.

\section{Materials and methods}

A population of 257 women ranging from 14 to 51 years old was recruited at the Department of Neurosciences, Section of Otolaryngology of Padova University. The population consisted of two groups: the first one (the study group) was composed of 109 women without nasal diseases and gynaecological disorders that used modern oral pill as contraception; the other group (control group) was composed of 148 healthy women volunteers who did not take OCP, had neither nasal diseases nor gynaecological disorders and self-reported regular menses (26-32 days) for the three previous cycles ${ }^{(14)}$. All women of the control group were recruited from students, colleagues, nurses and patients attending for problems other than the nose. On enrolment into the study, all subjects were asked to complete a SNOT 22 questionnaire ${ }^{(15)}$. Volunteers were also asked if they were experiencing nasal blockage, if they were smokers, allergic, asthmatic or had undergone any previous surgery on the nose and paranasal sinuses. All those female subjects who were non-smokers, non-asthmatic, without any previous sinonasal surgery, with a SNOT 22 score $<1$, who did not take $\beta$-blockers or corticosteroid entered into the study as control group. All females enrolled as the study group were non-smokers, nonasthmatic, without previous sinonasal surgery, but took OCP. While in the study group 9 women were excluded because of allergic disease, none in the other group was allergic or showed other exclusion criteria. Then, 100 women were finally considered as the study group for the present investigation.

All females of the study group used OCP containing between 0.02 to $0.03 \mathrm{mg}$ of ethynylestradiol and $3 \mathrm{mg}$ of progestins. The present investigation was conducted in accordance with the 1996 Helsinki Declaration and was approved by an internal ENT committee. Written informed consent was obtained from all participants before undertaking any study-related procedures.

A portable Youlten peak flow meter (Clement Clark International) was used for the measurement of PNIF and PNIF values were obtained as previously described ${ }^{(10,11)}$. In particular, the masks attached to the spirometer were chosen to fit tightly on each subject face without touching the nose. All subjects were tested while sitting and were encouraged to inhale as hard and fast as they could through the mask keeping the mouth closed starting from the end of a full expiration. Three satisfactory maximal inspirations were obtained and the highest of the three results was taken as the PNIF.

None of the females of the study group was tested in the bleeding phase; furthermore, none of the females of the control group reported to be in the periovulatory phase of the menstrual cycle, but during the secretory phase determined using basal temperature.

\section{Statistic analysis}

Welch two-sample t-test was used to compare mean PNIF, height and age values between the two groups. The power of the test used was obtained via simulations.

Statistical analysis was also undertaken with the objective of measuring the effect of estrogens (given sex and height), by obtaining a model relating the variable PNIF to these variables. The tests comprised the comparisons of the ratio of mean regression and mean residual sums of squares to an $\mathrm{F}$ distribution with appropriate degrees of freedom.

Generally, we adopted $5 \%$ as the critical level of significance in our tests. We also used standard residual and probability plots to verify the adequacy of the Normality assumption in our models.

\section{Results}

Mean and standard deviation (SD) of nasal flows of the females taking OCP and of the females of the control group are shown in Table 1.

SNOT 22 scores were similar between the two groups $(p=0.85)$ as all females taking OCP showed a SNOT 22 score $<1$.

Neither age nor height were statistically different between the two groups ( $p=0.191$ and 0.120 , respectively). Considering PNIF values in both groups, as usual ${ }^{(10-12)}$ we found a large residual variability. A plot of this variable against height is shown in Figure
Table 1. Mean and range values of Age, Height and PNIF of the 2 groups of study.

\begin{tabular}{|c|c|c|c|c|c|c|}
\hline \multirow[b]{2}{*}{ Variable } & \multicolumn{3}{|c|}{$\begin{array}{l}\text { Females taking OCP } \\
\qquad(n=100)\end{array}$} & \multicolumn{3}{|c|}{$\begin{array}{l}\text { Females not taking OCP } \\
\qquad(n=148)\end{array}$} \\
\hline & Mean & SD & Range & Mean & SD & Range \\
\hline Age (yr) & 30.5 & 8.5 & $16-51$ & 32.0 & 9.1 & $14-50$ \\
\hline Height (cm) & 165.1 & 6.6 & $150-183$ & 163.7 & 6.5 & $150-182$ \\
\hline PNIF (I/min) & 142.3 & 36.1 & $70-250$ & 133.6 & 35.8 & $55-240$ \\
\hline
\end{tabular}

Table 2. Summary of the estimates of the final model.

\begin{tabular}{llccc} 
& Estimate & SD & t value & $\operatorname{Pr}(>[\mathrm{t}])$ \\
\hline Intercept & 4.779 & 2.414 & 1.980 & 0.489 \\
\hline Contraception & 0.331 & 0.196 & 1.685 & 0.093 \\
\hline Height $(\mathrm{cm})$ & 0.041 & 0.015 & 2.767 & 0.006
\end{tabular}


1 where we used different symbols for cases and controls. Following previous experiences ${ }^{(10-12)}$, we used the transformation MODPNIF $=(\mathrm{PNIF}) 1 / 2$ to counter the problem of heterogeneity in variability.

Analysing the mean PNIF values difference between the two groups, Figure 2 compared the distributions of the MODPNIF. Box plots could not show a difference between the two groups. To exclude that the PNIF great variability found in the study could have hidden a PNIF significant difference between the two groups, calculations were made to assess the approximate power of the test procedure used. With the number of subjects considered, the power of the test in identifying a significant MODPNIF difference between the two groups was around 70\%. Such a level of power suggested that the test failure to obtain a significant MODPNIF values difference between the two groups was more likely to be due to a genuine lack of difference rather than a limitation of test discriminatory power.

We also fitted a model including age and height to measure the differences between cases and controls. Age was not significant once height was included in the model, therefore the final model used for current data analysis was:

\section{MODPNIF $=\beta 0+\beta 1$ CASES $+\beta 2$ HEIGHT $+\varepsilon$}

where $\varepsilon$ is a Normal random variable. The fit of the model was quite good presenting a p-value for the test $F$ of 0.0036 while residuals did not show particular patterns and qq-plot suggested quite a good fit for the normality of the residuals. Table 2 summarizes the final model estimate, showing that height had a significant effect $(p=0.0061)$, but not contraception $(p=0.093)$, showing again that from the study results there was no effect on PNIF due to the use of OCP.

\section{Discussion}

There are two types of estrogen receptors (ER): ER $\alpha$ and ER $\beta$. The first was discovered in 1958 by Jensen ${ }^{(16)}$, whereas ER $\beta$ was discovered in $1996^{(17)}$. A study published in 1981 showed that ER are present in the nasal mucosa and this was confirmed in a recent study conducted on nasal biopsies where ER $\beta$ number was shown to be positively related to nasal symptoms ${ }^{(18)}$. Female hormones have been suspected of affecting nasal physiology for many years. Although the mechanism by which this occurs remains to be fully elucidated, it is well known that pregnant women often complain of nasal obstruction ${ }^{(19)}$. Although nasal congestion during pregnancy was already described in $1898^{(20)}$, only in 1999 Ellegard and Karlsson have given a definition of the pregnancy-induced rhinitis as "a nasal congestion present in the last 6 or more weeks of pregnancy without other signs of respiratory tract infection and with no known allergic causes, disappearing completely within 2 weeks

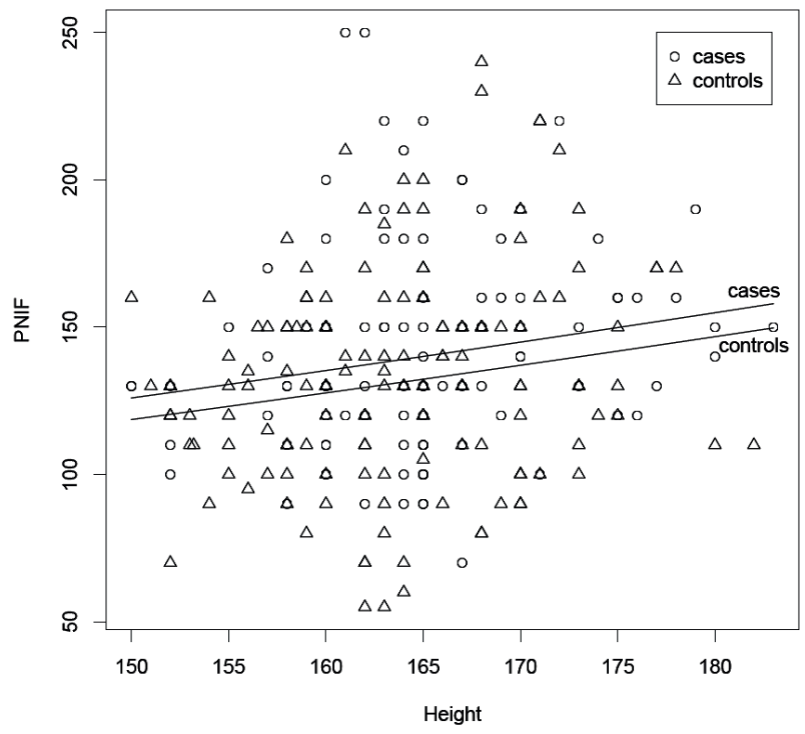

Figure 1. PNIF (I/min) against height $(\mathrm{cm})$, for females taking OCP (cases) and females not taking OCP (controls).

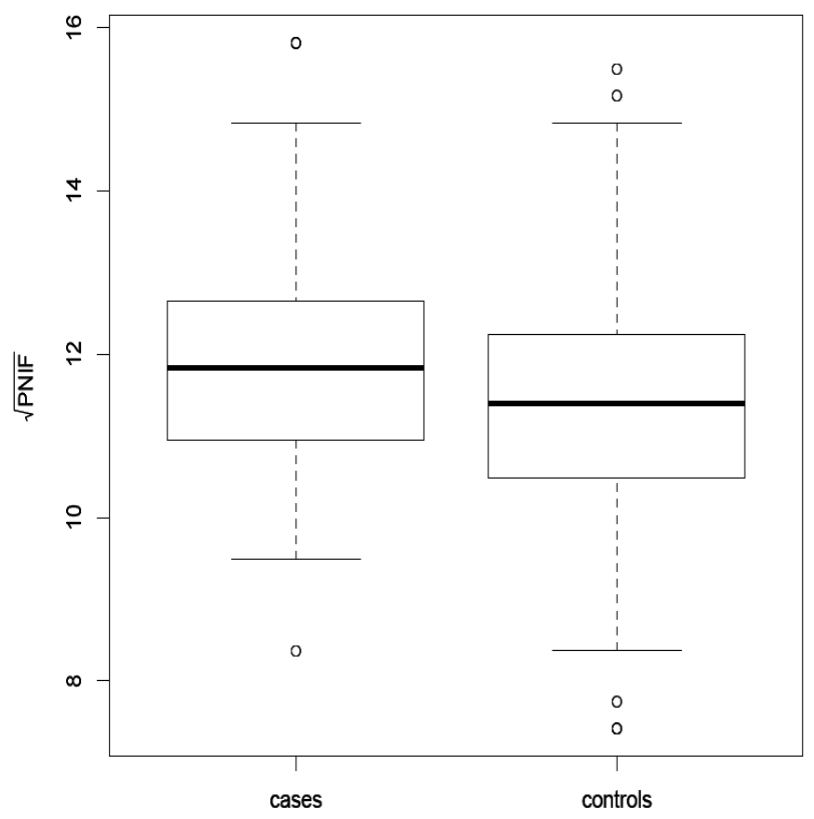

Figure 2. Boxplots of MODPNIF for females taking OCP (cases) and females not taking OCP (controls).

after delivery" (21). A recent review has underlined the fact that, although temporary, pregnancy-induced rhinitis can profoundly affect quality of life ${ }^{(19)}$.

There are other conditions that appear to be related to raised ovarian hormones, either natural, such as menstrual cycle, or induced, such as in cases of menopausal women taking hormone replacement. In 2004, decreased nasal patency corresponding 
to the estrogen peak at the periovulatory stage of menstruation was demonstrated ${ }^{(22)}$. In contrast, no difference in nasal physiology was found in a group of women before and during hormone replacement therapy ${ }^{(23)}$.

Although in 1984 Topozzada and co-workers showed squamous metaplasia and interepithelial oedema in the nasal mucosa of symptomatic females taking OCP ${ }^{(4)}$, in a recent study conducted on 11 young, healthy females, exogenous ovarian hormones have been shown to not affect nasal function. The authors concluded that the lack of nasal congestion with modern oral contraceptive therapy could reflect the lower estrogen content of modern OCP ${ }^{(5)}$.

In the present study, we analysed a much larger group of females taking OCP and compared them to a large cohort of females not taking OCP. We studied nasal patency using PNIF, as it is a reliable and simple method that showed a reasonable correlation with anterior active rhinomanometry both in healthy and pathologic populations ${ }^{(10,11,13)}$. Moreover, normal and pathologic PNIF values have been published in the last years making PNIF an attractive method for clinical practice ${ }^{(13)}$.

No statistical differences were found on PNIF values between the two groups of study and no nasal congestion was reported by the females who took oral contraceptive pills, as SNOT 22 scores were similar between the two groups.
In conclusion, the present study could not show that OCP have effects on nasal function. From the model presented in the study only height seemed to influence nasal flows measured by PNIF. This result is in line with previous reports ${ }^{(10-13)}$ and could be easily explained by the fact that there is a correlation between pulmonary airflow and nasal airflow ${ }^{(11)}$. As pulmonary volumes are strictly related to patients' height ${ }^{(24)}$, also PNIF is strictly related to patients' height. In this study, in contrast to what seen in others ${ }^{(10-13)}$, there was no effect of age on the model, meaning that age did not affect PNIF. This was probably due to the fact that the volunteers enrolled in the present study were of similar ages, about $50 \%$ of them in each group were between 20 and 30 years old.

\section{Acknowledgement}

The authors would like to thank all volunteers who participated in the study.

\section{Authorship contribution}

GO: Principal investigator; EC: Design of the study and discussion; Vl: Recruitment of volunteers, drafting of the paper; BS: Statistics; AS: Rhinological discussion; GKS: Critical revision for important intelectual content.

\section{Conflicts of Interest}

No conflict of interest exists.

\section{References}

1. Bateman ND, Woolford TJ. The rhinological side-effect of systemic drugs. Clin Otolaryngol. 2003; 28: 381-385.

2. Caruso S, Serra A, Grillo C, Agnello C, Di Mari L, Cianci A. Prospective study on the cytological aspects of the nasal respiratory epithelium in premenopausal women taking $30 \mathrm{mcg}$ ethinylestradiol and $3 \mathrm{mg}$ drospirenone oral contraceptive. Contraception. 2008; 77: 344-349.

3. Helmi AM, El Ghazzawi IF, Mandour MA Shehata MA. The effect of oestrogen on the nasal respiratory mucosa. An experimental histopathological and histochemical study. J Laryngol Otol. 1975; 89: 1229-1241.

4. Toppozada H, Toppozada M, El-Ghazzawi I, Elwany S. The human respiratory nasa mucosa in females using contraceptive pills. An ultramicroscopic and histochemical study. J Laryngol Otol. 1984; 98: 43-51.

5. Wolstenholme CR, Philpott CM, Oloto EJ, Murty GE. Does the use of the combined oral contraceptive pill cause changes in the nasal physiology in young women? Am J Rhinol. 2006; 20: 238-240

6. Franklin KA, Holmgren PA, Jönsson F, Poromaa N, Stenlund H, Svanborg E. Snoring, pregnancy-induced hypertension, and growth retardation of the fetus. Chest. 2000; 117: 137-141.
7. Ellegård EK. Pregnancy rhinitis. Immunol Allergy Clin North Am. 2006; 26: 119-135.

8. Bhagat DR, Chowdhary A, Verma S, Jyotsana. Physiological changes in ENT during pregnancy. Indian J Otolaryngol Head Neck Surg. 2006; 58: 268-270.

9. Starling-Schwanz R, Peake HL, Salome CM et al. Repeatability of peak nasal inspiratory flow measurements and utility for assessing the severity of rhinitis. Allergy. 2005; 60: 795-800.

10. Ottaviano G, Scadding GK, Coles S, Lund VJ. Peak nasal inspiratory flow. Normal range in adult population. Rhinology. 2006; 44 32-35.

11. Ottaviano G, Lund VJ, Coles S, Staffieri A, Scadding GK. Does peak nasal inspiratory flow relate to peak expiratory flow? Rhinology. 2008; 46: 200-203.

12. Ottaviano G, Scadding GK, Scarpa B, Accordi D, Staffieri A, Lund VJ. Unilateral peak nasal inspiratory flow, normal values in adult population. Rhinology. 2012; 50: 386-392.

13. Ottaviano G, Lund VJ, Nardello E, et al. Comparison between unilateral PNIF and rhinomanometry in healthy and obstructed noses. Rhinology 2014; 52: 25-30.

14. Morofushi M, Shinohara K, Funabashi T, Kimura F. Positive relationship between menstrual synchrony and ability to smell 5alpha-androst-16-en-3alpha-ol. Chem
Senses. 2000; 25: 407-411.

15. Hopkins C, Gillett S, Slack R, Lund VJ, Browne JP. Psychometric validity of the 22-item Sinonasal Outcome Test. Clin Otolaryngol. 2009; 34: 447-454.

16. Jensen EV. On the mechanism of estrogen action. Perspect Biol Med. 1962; 6: 47-59.

17. Enmark E, Gustafsson JA. Oestrogen receptors - an overview. J Intern Med. 1999; 246: 133-138.

18. Philpott CM, Wild DC, Wolstensholme CR, Murty GE. The presence of ovarian hormone receptors in the nasal mucosa and their relationship to nasal symptoms. Rhinology. 2008; 46: 221-225.

19. Orban N, Maughan E, Bleach N. Pregnancyinduced rhinitis. Rhinology. 2013; 51: 111119

20. MacKenzie JN. The physiological and pathological relations between the nose and the sexual apparatus of man. Alienist and Neurol. 1898; 19: 219-239.

21. Ellegard E, Karlsson G. Nasal congestion during pregnancy. Clin Otolaryngol. 1999; 24: 307-311.

22. Philpott CM, Robinson AM, Murty GE. Nasal pathophysiology and its relationship to the female ovarian hormones. J Otolaryngol Head Neck Surg. 2008; 37: 540-546.

23. Wild DC, Philpott CM, Wolstenholme CR, Murty GE. Does hormone replacement 
therapy in post-menopausal women have any effect upon nasal physiology? J Laryngol Otol. 2008; 122: 707-710.

24. Gregg I, Nunn AJ. Peak expiratory flow in normal subjects. Br Med J. 1973; 3: 282-284.
Giancarlo Ottaviano, MD, PhD

Department of Neurosciences

Otolaryngology Section

University of Padova

Via Giustiniani 2
35128 Padova

Italy

Tel. +39-(0)49-821 2029

Fax: +39-(0)49-821 3113

E-mail: giancarlo.ottaviano@unipd.it

\section{ADVERTISEMENT}

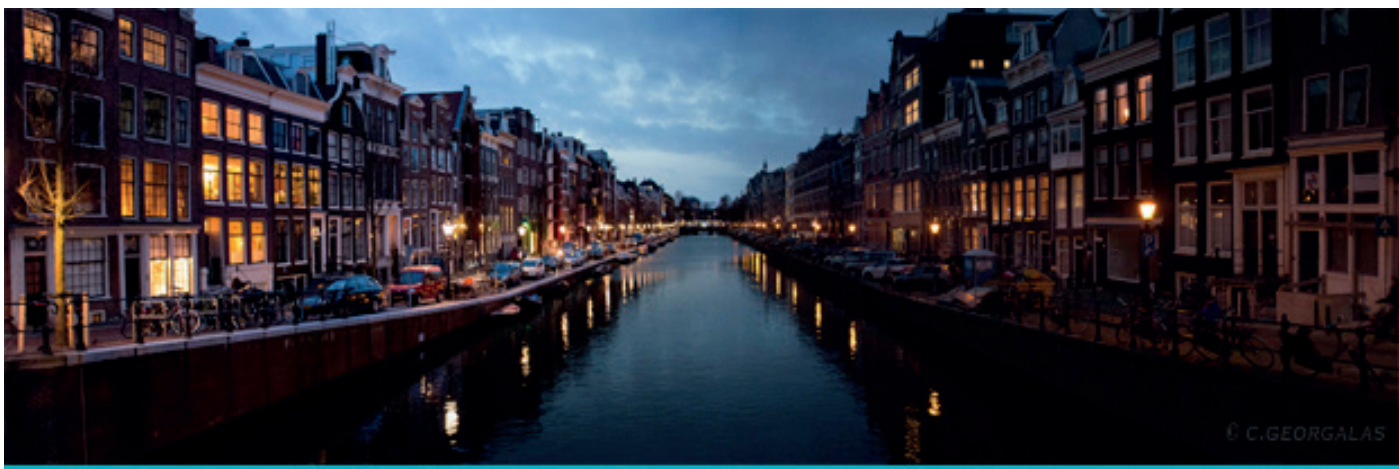

\section{2nd International Endoscopic Skull Base Course}

\section{www.skullbasecourse.nl}

\section{7 - 18 - 19 June 2015 Amsterdam}

\section{Course Directors: Christos Georgalas \& Wouter van Furth}

- For Neurosurgeons and ENT's

- Step by step "How I do It" demonstrations and dissections

- $1: 3$ faculty to participant ratio

- Fresh Frozen specimens

- Neuro-Navigation and High Speed Endoscopic Drills

- Free DVD with HD dissections included

Price: 1400 euros full course incl. dissections

1200 euros for residents /

combined neurosurgeon - ent team

Lectures only - excl. dissections :

700 euros / 600 euros for residents

Course secretariat: M. van Huiden

m.b.vanhuiden@amc.uva.nl

info@skullbasecourse.nl
Academic Medical Center, University of Amsterdam 1100 DD Amsterdam, The Netherlands

tel. 003120 5668586/fax. 0031205669573 